\title{
Practical Aspects of the Use of Healthcare Failure Mode and Effects Analysis Tool in The Risk Management of Pediatric Emergency Department: The Scrutiny in Iran
}

\author{
(1) Yasamin Molavi-Taleghani1, (1) Asma Abdollhayar2, (1) Mahmoud Nekoei-Moghadam3, \\ (D) Hojjat Sheikhbardsiri4
}

${ }^{1}$ Isfahan University of Medical Sciences, Health Management and Economics Research Center, Faculty of Management and Medical Informatics, Isfahan, Iran

2Kerman University of Medical Sciences Hospital Afzalipour, Master of Science in Nursing Orientation Ward Nicu, Kerman, Iran

${ }^{3}$ Kerman University of Medical Sciences Research Center for Health Services Management, Institute for Future Studies in Health, Kerman, Iran

${ }^{4}$ Kerman University of Medical Sciences, Department of Emergency Operation Center, Disasters and Emergencies Management Center, Kerman, Iran

\begin{abstract}
Aim: The Emergency Department is one of the most challenging wards of the hospital for studying patient safety and the prevention of treatment errors is the basic rule in the quality of health care. The present study was conducted to evaluate the selected risk processes of Pediatric Emergency of Qaem Educational Hospital in Mashhad by the Healthcare Failure Mode and Effects Analysis (HFMEA) methodology.

Materials and Methods: A mixed method was used to analyze failure modes and their effects with HFMEA. Five high-risk processes of the Pediatric Emergency were identified and analyzed. To classify failure modes, nursing errors in clinical management model; for classifying factors affecting error, the approved model by the United Kingdom National Health System; and for determining solutions for improvement, Theory of Inventive Problem Solving was used.

Results: In 5 selected processes, 28 steps, 80 sub-processes and 254 potential failure modes were identified with HFMEA. Thirty-seven (14.5\%) failure modes as high-risk errors were detected and transferred to the decision tree. The most and the least failure modes were placed in the categories of care errors as $62.3 \%$, and knowledge and skill as $8.1 \%$ respectively. Also, $23.6 \%$ of preventive measures were in the category of human resource management strategy.

Conclusion: Using the proactive method of HFMEA for identifying the possible failure of treatment procedures, determining the effective cause on each failure mode and proposing the improvement strategies, has high efficiency and effectiveness.

Keywords: Emergency, Healthcare Failure Mode and Effects Analysis, pediatric, risk management.
\end{abstract}

\section{Introduction}

Medical failure poses a real threat to both the health system and the patients' health. It is likely to happen in all diagnosis and treatment stages, which is often costly and reduces the quality of life of patients (1). Hence, maintaining patient safety is a major concern in the health care system (2). Furthermore, the Emergency Department is one of the most challenging departments of the hospital for for the study of patient safety because of its unique features (3). In emergency situations, time for critical thinking, which results in delays in decision making and consequently an increase 
in adverse events, is very short (3). Preventable errors are one of the main factors of patient death and disability. Based on the results of a study, nearly $40 \%$ of inpatients have become disabled, and $2.3 \%$ of these disabilities were related to preventable errors (4). Totally, $3 \%$ of all hospital errors are related to the emergency department (5). Furthermore, approximately one-third of the patients referring to hospitals are for the pediatric emergency department, and this department has been identified as a high-risk area in the health care system (6). Adverse events have resulted in an extra expenditure of about 37 billion US dollars in America, and one to two billion pounds in England (7). Prevention of medical errors is one of the basic principles in the quality of health care (7). In all quality improvement programs, an error prevention and risk management approach is one of the pivotal aspects of creating, establishing, and deploying management systems in organizations (8). One of the most promising risk prevention programs from the viewpoint of the National Center for Patient Safety (NCPS) and the US Accreditation Commission, is Healthcare Failure Mode and Effects Analysis (HFMEA) (9). In fact, HFMA is a systematic and predictive strategy which is designed specifically for healthcare organizations to identify and prevent errors before they happen (10). This method is used extensively in order to identify errors and improve patient safety standards. Results of studies indicate that from 2008 to 2009, and after the implementation of risk assessment programs by NCPS, the number of adverse medical events has reduced from 3643 to 2412 (11). The administration of patient safety plans in the Emergency Department has improved the quality of healthcare and patient satisfaction (12), and the Emergency Department is one of the most important departments of the hospital (13), as well as being the first department to provide healthcare for many patients (14). Therefore, the present study was conducted to evaluate the selected risk processes of pediatric emergency of a treatment-educational Qaem center in Mashhad by the HFMEA methodology.

\section{Materials and Methods}

\section{Research Design and Setting}

This study was approved by the ethical committee of Mashhad University of Medical Sciences prior to the collection of the data in January 2013 (approval number: 911089). Written informed consent was recruited from each participant. A mixed-method including qualitative action research and descriptive quantitative cross-sectional study was conducted in 2016. Qaem Hospital is ranked as one of the largest educational and therapeutic centers at regional and national levels, with a total of 870 active beds, 18 units and 7 emergency rooms, with Para clinical services and clinics. Children's Emergency Department of Qaem Hospital undertakes the following services: reception and outpatient treatment; performing, sending and following-up laboratory tests; serum attachment; physiotherapy; tension test; catheterization; electroencephalogram; performing, sending and following the response of the cerebrospinal fluid; vaccination, washing, wound dressing of the patient; patient's initial visit, nominal group technique, electromyography-nerve conduction velocity, magnetic resonance imaging (MRI), computed tomography scan; neonatal lactation; endoscopy; liver biopsy; primary visit; patient radiology, Sonography, suction, intubation, auditory test, optometry test, delivery of blood transfusion and blood products, phototherapy and determining the condition of the patient (transferring the patient to other departments for continued care or discharge). In this study five high-risk processes of pediatric emergency department were identified and analyzed in Qaem TreatmentEducational Center. It should be noted that the temporary admission rate in the Pediatric Emergency had an average of 396 people per month (200 temporary admissions in the morning shift, 110 admissions in the evening shift and 86 in the night shift) in 2015.

\section{Data Collection}

Data gathering was done through focus groups, interviews, observation, and brainstorming. The validity of this study was controlled by the consensus of team members at the end of each phase. The stages of this research were determined according to the five stages of the analysis of the states and effects of health care errors by the National Center for Patient Safety (9), and were carried out as follows, which, as the circumstances require, have differences with the proposed model:

\section{Step 1: Choosing a Risky Process}

Via the "voting method using rating" technique, ten members of the pediatric emergency department were asked to rank five of the 26 processes listed in the section, considering the problem effects on the patients' dissatisfaction, the likelihood of injuries by the problems and the need to fix the problems. Then, the data obtained from the voting was finalized according to the matrix or the Breda function and five priority processes were selected for risk management $(15,16)$.

\section{Step 2: Assembling the Team}

Qaem Hospital's emergency staff includes a supervisor, 8 nurses, 3 staff members, one children's emergency department director, 5 pediatricians, a secretary, two crew members and 6 pediatric residents. In the staffing program, the staffing of the emergency medical staff is carried out three times morning, evening and night. In this process, 15 persons participated as the members of HFMEA team, including the responsible person of risk management (team leader), an expert in health services (team advisor), an assistant professor in the emergency department, head of the emergency department, a supervisor, two assistants 
(residents), two nurses, the chief of the laboratory, a laboratory expert, a blood bank expert, MRI expert, and head of the MRI department.

\section{Step 3: Graphically Describing the Processes}

At this stage, the charts of the selected processes and their sub-processes were drawn through the observation and individual interviewing method, and the accuracy of the diagram of the flow of processes and sub-processes was modified and approved by the team members in a group discussion session, and was drawn in the form of a process flowchart with Visio software.

\section{Step 4: Conducting Hazard Analysis that Took Place in Four Phases}

First phase: Determination of potential failure modes

At this stage, the error states of each of the subprocesses of the selected sections were identified by the triangular method (17), and classified according to the classes of the "Nursing Error Management Association" model (18). Failure modes according to the nursing errors in clinical management model were categorized in 4 main groups of communication; care process, administrative, knowledge, and skilled based error (18).

Second Phase: Determination of the hazard score

The hazard Score was determined using the Error Scoring Matrix (the product of the two elements of the severity and probability of occurrence of the error) and was recorded in the HFMEA worksheet. The errors were grouped according to their hazard score into four intervention levels, i.e., emergency, urgency, programming, and monitoring (Table I) (19).

\section{Third Phase: Designing decision making tree}

The non-acceptable risks (risk score level more than 8) were transferred to the decision tree. Decisions for proceeding or stopping each of the failure modes was made based on three items; weakness points, existing control, and detectability.

Fourth Phase: In this phase, the failure mode causes of each failure mode, and where the decision is to "Proceed" were categorized into 9 root causes in the consultative cause-effect meetings, and in the format of an approved model by the UK National Health System (20).

Step 5: Actions and Measurement of Consequences which Were Performed in Two Phases

\begin{tabular}{|l|l|l|l|l|l|}
\hline \multicolumn{5}{|c|}{ Table I. Error scoring matrix and classification of interventional levels } \\
\hline $\begin{array}{l}\text { Intervention } \\
\text { level }\end{array}$ & $\begin{array}{l}\text { Severity\& } \\
\text { probability }\end{array}$ & $\begin{array}{l}\text { Catastrophic } \\
(\mathbf{4})\end{array}$ & $\begin{array}{l}\text { Important } \\
(\mathbf{3})\end{array}$ & $\begin{array}{l}\text { Intermediate } \\
\text { (2) }\end{array}$ & $\begin{array}{l}\text { Minor } \\
\text { (1) }\end{array}$ \\
\hline Emergency & Usual (4) & 16 & 12 & 8 & 4 \\
\hline Urgent & $\begin{array}{l}\text { Sometimes } \\
\text { (3) }\end{array}$ & 12 & 9 & 6 & 3 \\
\hline Programming & Unusual (2) & 8 & 6 & 4 & 2 \\
\hline Monitoring & Rare (1) & 4 & 3 & 2 & 1 \\
\hline
\end{tabular}

\section{Phase 1: Definition of Error Control Strategies}

In this phase, suggested coping strategies were proposed for the causes of errors in the decision tree in the form of acceptance, control, and elimination of errors. The second phase, redesigning the process: improving strategies for each cause of error with a score $\geq 8$ in the team meetings through "theory of the problem solving by an inventive method" $(21,22)$ were provided and classified with inspiring by the proposed model of "classification of preventive strategies in the incidence of medical errors" $(7,23)$, and finally decisions were made about the practicability of the implementation of any approach with regard to the resources of the organization.

\section{Statistical Analysis}

Quantitative Analysis: For the quantitative analysis of the variables related to the failure mode analysis phase, descriptive statistics were calculated in Excel software, including frequency, percent, and mean. Also, for the quantitative analysis and determination of the probability of the failures, the sum of the team's scores was used with consideration of a coefficient for each team member. For the severity of the failures, the team members' consensus along with the consideration of weight for the severity of failures was used. In the final worksheet, we calculated and documented the sum of the failure mode severity scores according to team members' opinions. By considering weights for the failure mode severity dimensions we calculated the sum of the failure mode probability scores based on the involved personnel's opinions (also by considering the coefficient for each person).

Qualitative Analysis: Content analysis was done on the data collected from the individual interviews in order to put them in the organized forms. To do so, all the interviews with the team members were transcribed, and, for the sake of understanding the transcriptions, they were read, and repetitions were omitted and the significant issues were extracted. Therefore, a list of all of the team members' opinions was prepared. Analysis of the data from the brainstorming, cause and effect, and problem-solving sessions was done based on the general agreement of the team members. It should be noted that the time taken to carry out the study was 38 hours.

\section{Results}

By voting method using rating, 5 out of 20 identified processes in pediatric emergency, with Borda number of (37 score) for the process of MRI implementation (32 score) for the process of performing, sending and tracking the laboratory results (25 score) for the process of implementing the IP (18 score) for transferring CSF specimen and following up the results and (7 score) for the process of setup IV line, were chosen. According to the results, for 5 selected processes per 28 listed steps, 80 sub-processes and 254 failure modes were identified. According to table 2, the interventional levels showed that $1.2 \%$ of the error modes 
Table II. Frequency distribution of failure modes in each area of the error scoring matrix and classification of failure modes based on the model of Management Association of nursing error for the selected emergency pediatric processes

\begin{tabular}{|c|c|c|c|c|c|c|c|c|c|c|c|c|c|}
\hline \multirow[b]{2}{*}{ 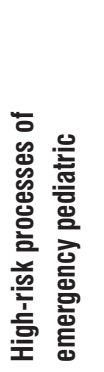 } & \multirow[t]{2}{*}{ Activities } & \multirow[b]{2}{*}{ 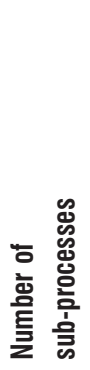 } & \multirow[b]{2}{*}{ 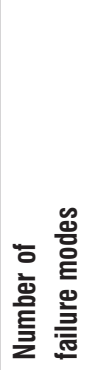 } & \multirow{2}{*}{ 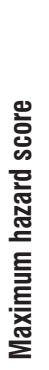 } & \multirow{2}{*}{ 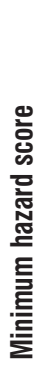 } & \multicolumn{4}{|c|}{$\begin{array}{l}\text { Number of intervention levels } \\
\text { categories }\end{array}$} & \multicolumn{4}{|c|}{$\begin{array}{l}\text { Frequency percentage of failure } \\
\text { modes based on association model } \\
\text { of "management of nursing error" }\end{array}$} \\
\hline & & & & & & 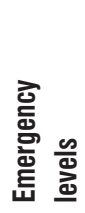 & 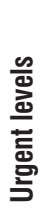 & 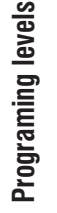 & 을 & 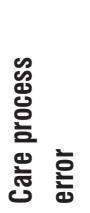 & 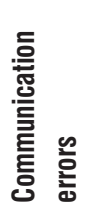 & 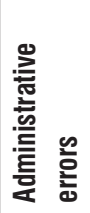 & 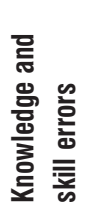 \\
\hline \multirow{5}{*}{ 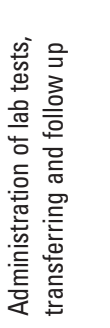 } & Order for lab test & 6 & 19 & 9 & 2 & 0 & 3 & 14 & 2 & 17 & 7 & 0 & 1 \\
\hline & $\begin{array}{l}\text { Sampling and transferring the } \\
\text { sample }\end{array}$ & 4 & 17 & 9 & 3 & 0 & 1 & 15 & 1 & 13 & 2 & 5 & 4 \\
\hline & Sample analysis & 4 & 15 & 9 & 6 & 0 & 2 & 13 & 0 & 14 & 0 & 6 & 2 \\
\hline & Preparing test results & 1 & 4 & 9 & 6 & 0 & 3 & 1 & 0 & 4 & 0 & 2 & 0 \\
\hline & $\begin{array}{l}\text { Reporting the test result to the } \\
\text { doctor }\end{array}$ & 2 & 5 & 6 & 4 & 0 & 0 & 5 & 0 & 4 & 0 & 0 & 1 \\
\hline \multirow{6}{*}{$\overline{\underline{\Sigma}}$} & Order for MRI & 2 & 7 & 9 & 4 & 0 & 2 & 5 & 0 & 5 & 1 & 0 & 1 \\
\hline & $\begin{array}{l}\text { Informing the ward secretary about } \\
\text { MRI order }\end{array}$ & 3 & 11 & 9 & 2 & 0 & 1 & 8 & 2 & 4 & 3 & 1 & 2 \\
\hline & Reporting MRI order to MRI ward & 3 & 8 & 6 & 4 & 0 & 0 & 8 & 0 & 3 & 5 & 2 & 0 \\
\hline & $\begin{array}{l}\text { Transferring the patient to MRI } \\
\text { ward }\end{array}$ & 2 & 8 & 6 & 4 & 0 & 0 & 8 & 0 & 9 & 0 & 1 & 0 \\
\hline & MRI implementation & 1 & 4 & 9 & 2 & 0 & 1 & 2 & 1 & 3 & 0 & 2 & 0 \\
\hline & $\begin{array}{l}\text { Taking results and reporting that to } \\
\text { the doctor }\end{array}$ & 2 & 5 & 6 & 2 & 0 & 0 & 3 & 2 & 5 & 0 & 1 & 1 \\
\hline \multirow{8}{*}{ 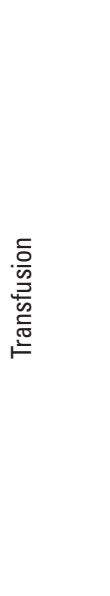 } & $\begin{array}{l}\text { Doctor order for blood transfusion } \\
\text { and checking doctor order }\end{array}$ & 3 & 10 & 9 & 4 & 0 & 2 & 8 & 0 & 7 & 1 & 5 & 1 \\
\hline & Sampling & 4 & 13 & 6 & 3 & 0 & 1 & 10 & 2 & 12 & 3 & 2 & 1 \\
\hline & $\begin{array}{l}\text { Administration of required tests } \\
\text { before transfusion }\end{array}$ & 5 & 14 & 12 & 3 & 2 & 3 & 9 & 0 & 8 & 3 & 4 & 0 \\
\hline & $\begin{array}{l}\text { Requesting blood from blood bank } \\
\text { by pediatrics emergency ward }\end{array}$ & 3 & 10 & 12 & 4 & 1 & 2 & 7 & 0 & 7 & 1 & 1 & 0 \\
\hline & $\begin{array}{l}\text { Reception of blood from blood bank } \\
\text { by pediatrics emergency ward }\end{array}$ & 2 & 4 & 6 & 4 & 0 & 0 & 4 & 0 & 3 & 0 & 1 & 0 \\
\hline & $\begin{array}{l}\text { Implementing required actions } \\
\text { before transfusion }\end{array}$ & 3 & 13 & 8 & 4 & 0 & 2 & 11 & 0 & 9 & 3 & 1 & 0 \\
\hline & Starting blood transfusion & 2 & 7 & 8 & 4 & 0 & 2 & 5 & 0 & 5 & 3 & 0 & 0 \\
\hline & $\begin{array}{l}\text { Recording transfusion in the } \\
\text { patient file }\end{array}$ & 2 & 6 & 9 & 4 & 0 & 1 & 5 & 0 & 0 & 4 & 1 & 0 \\
\hline \multirow{5}{*}{ 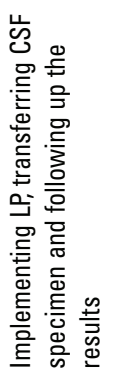 } & Doctor order for LP & 2 & 8 & 9 & 3 & 0 & 2 & 4 & 2 & 8 & 2 & 2 & 0 \\
\hline & $\begin{array}{l}\text { Preparing equipment and } \\
\text { administrating LP }\end{array}$ & 4 & 14 & 9 & 2 & 0 & 3 & 5 & 6 & 15 & 3 & 2 & 2 \\
\hline & $\begin{array}{l}\text { Preparing and transferring CSF } \\
\text { specimen to the lab }\end{array}$ & 3 & 8 & 6 & 4 & 0 & 0 & 8 & 0 & 3 & 0 & 6 & 0 \\
\hline & Preparing results by the lab & 3 & 9 & 9 & 4 & 0 & 2 & 7 & 0 & 8 & 0 & 3 & 1 \\
\hline & $\begin{array}{l}\text { Transferring result to the doctor, } \\
\text { interpretation of the results and } \\
\text { starting action based on the result }\end{array}$ & 2 & 3 & 6 & 4 & 0 & 0 & 3 & 0 & 3 & 0 & 1 & 1 \\
\hline
\end{tabular}




\section{Table II. Continue}

\begin{tabular}{|c|c|c|c|c|c|c|c|c|c|c|c|c|c|}
\hline \multirow{4}{*}{ 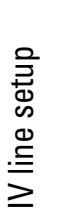 } & Checking for doctor order & 2 & 4 & 4 & 4 & 0 & 0 & 4 & 0 & 3 & 1 & 1 & 0 \\
\hline & Preparing IV set & 4 & 9 & 9 & 4 & 0 & 1 & 8 & 0 & 10 & 2 & 1 & 2 \\
\hline & Setting up IV line & 4 & 12 & 6 & 2 & 0 & 0 & 9 & 3 & 12 & 2 & 1 & 5 \\
\hline & $\begin{array}{l}\text { Patient observation and recording } \\
\text { IV line setup }\end{array}$ & 2 & 7 & 4 & 2 & 0 & 0 & 5 & 2 & 8 & 2 & 0 & 0 \\
\hline \multicolumn{2}{|l|}{ Total } & 80 & 254 & 214 & 98 & 3 & 34 & 194 & 23 & 202 & 45 & 51 & 26 \\
\hline
\end{tabular}

Hint: It may put failure modes in different categories based on management association of nursing error, CSF: Cerebrospinal fluid, LP: Lumbar puncture, MRI: Magnetic resonance imaging, IV: Intravenous

Table III. Classification of the basic causes of failure modes with error score $\geq 8$ based on Eindhoven model

\begin{tabular}{|c|c|c|c|c|c|c|}
\hline Error cause & Setup IV line & $\begin{array}{l}\text { Laboratory } \\
\text { management }\end{array}$ & $\begin{array}{l}\text { Delivery, } \\
\text { transfusion of } \\
\text { blood and blood } \\
\text { products }\end{array}$ & MRI implementation & $\begin{array}{l}\text { Implementing LP, } \\
\text { transferring CSF } \\
\text { specimen and following } \\
\text { up the results }\end{array}$ & $\begin{array}{l}\text { Total root } \\
\text { causes based on } \\
\text { effective factors }\end{array}$ \\
\hline $\begin{array}{l}\text { Factors related to patient and } \\
\text { patient caregiver }\end{array}$ & 1 & 1 & 1 & 1 & 6 & 10 \\
\hline Factors related to personnel & 0 & 3 & 6 & 2 & 2 & 13 \\
\hline Task factors & 0 & 2 & 6 & 0 & 0 & 8 \\
\hline Communication factors & 1 & 4 & 3 & 3 & 2 & 13 \\
\hline Equipment factors & 0 & 3 & 3 & 0 & 1 & 7 \\
\hline Environmental factors & 0 & 6 & 8 & 1 & 2 & 17 \\
\hline Organization factors & 0 & 2 & 3 & 2 & 1 & 8 \\
\hline Educational factors & 1 & 6 & 7 & 1 & 5 & 20 \\
\hline Team factors & 1 & 2 & 4 & 2 & 1 & 10 \\
\hline $\begin{array}{l}\text { Total root causes based on the } \\
\text { process }\end{array}$ & 4 & 29 & 41 & 12 & 20 & 106 \\
\hline
\end{tabular}

CSF: Cerebrospinal fluid, LP: Lumbar puncture, MRI: Magnetic resonance imaging IV: Intravenous

were related to the emergency levels intervention, $13.3 \%$ to urgent, $76.3 \%$ to programmed, and $9.1 \%$ were related to the monitoring area. Also, the number of identified failure modes, the number of intervention levels and the classification of the failure modes for the selected processes based on the proposed model were shown by the association of "management of nursing error". According to Table II, $(62.3 \%)$ of the failure modes related to care process error; $(13.8 \%)$ to communication errors; $(15.7 \%)$ to administrative errors; and $(8.1 \%)$ to knowledge and skill errors. In the next step, from the 254 detected failure modes, 37 (14.5\%) were recognized as high-risk and unacceptable (hazard score of 8 and higher) and were transferred to the decision tree (Table III). In Table III, classification of the causes of high-risk and non-acceptable risk (hazard score $\geq 8$ ) is shown based on an approved model by the UK National Health System. According to table 3, among the 106 effective causes detected in the high-risk failure modes of the decision tree, $9.4 \%$ related to team factors; $7.5 \%$ to organizational factors; $12.2 \%$ to communication factors; $7.5 \%$ to task factors; $12.2 \%$ to personnel factors; $16.1 \%$ to environment factors; $9.4 \%$ to patient factors; $18.8 \%$ to education factors, and $6.6 \%$ to facilities and technologies. Table IV, Phase I, Definition of Error Control Strategies: In this phase, suggested coping strategies were proposed for the causes of errors in the decision tree in the form of acceptance, control, and elimination of errors. Strategies suggested opposing the contributing factors to each failure mode were presented in the forms of acceptance (25\%), control (58.3\%), and

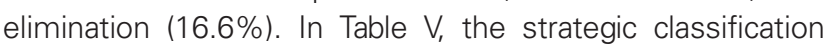
and preventive approaches proposed by the problem-solving theory are shown based on the proposed model. According to Table $\mathrm{V}$, among the 106 strategies detected in the highrisk failure modes of the decision tree, $23.6 \%$ related to human resource management; $2.9 \%$ to the installation of electronic prescribing system; $5.9 \%$ related to making people accountable for patient's safety; $5.9 \%$ related to medical equipment management and process standardization; $4.1 \%$ to the improvement of the patient identification process; $2.6 \%$ related to making clear and transparent policies and procedures; $3.2 \%$ to making sure of the availability of a suitable technology for quality improvement; $7.6 \%$ to the continuous training and briefing of care providers at the beginning of employment; $11.2 \%$ related to the participation 
Table IV. The worksheet of failure modes techniques and Healthcare Failure Mode and Effects Analysis for some high-risk failure modes of the selected pediatric emergency processes

\begin{tabular}{|c|c|c|c|c|c|c|c|c|c|c|}
\hline \multicolumn{9}{|l|}{ Hazard analysis } & \multicolumn{2}{|c|}{ Action and outcome measures } \\
\hline \multirow[t]{2}{*}{ Failure mode } & \multirow[t]{2}{*}{ Potential causes } & \multicolumn{3}{|c|}{ Scoring } & \multicolumn{3}{|c|}{ Decision tree analysis } & \multirow[b]{2}{*}{ 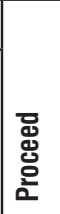 } & \multirow[b]{2}{*}{ 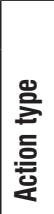 } & \multirow[t]{2}{*}{ Actions or rationale for stopping } \\
\hline & & 咅 & 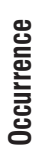 & $\begin{array}{l}\text { 몬 인 } \\
\text { ్ㅗㅇ }\end{array}$ & 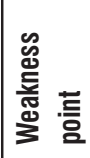 & 믈 옿 & 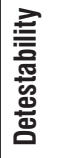 & & & \\
\hline \multirow{4}{*}{$\begin{array}{l}\text { Slip in checking the } \\
\text { blood request form by } \\
\text { the blood bank while } \\
\text { delivering the blood } \\
\text { bag }\end{array}$} & $\longrightarrow$ & 3 & 4 & 12 & $\longrightarrow$ & No & No & Yes & & \\
\hline & $\begin{array}{l}\text { A) temporal high } \\
\text { work load of blood } \\
\text { bank }\end{array}$ & 3 & 2 & 6 & no & - & - & No & A & $\begin{array}{l}\text { 1) Stress management and tasks } \\
\text { distribution }\end{array}$ \\
\hline & $\begin{array}{l}\text { B) Lack of } \\
\text { awarness of } \\
\text { importance } \\
\text { of the issue } \\
\text { and necessary } \\
\text { evaluation by the } \\
\text { blood bank }\end{array}$ & 3 & 3 & 9 & $\longrightarrow$ & No & No & Yes & C & $\begin{array}{l}\text { 1) Developing the staff performance } \\
\text { evaluation scales, based on the mistake that } \\
\text { occurred } \\
\text { 2) Annual evaluation of personnel of } \\
\text { appropriate blood transfusion process } \\
\text { 3) Training physicians about the "right } \\
\text { patients, right time and right blood" guideline } \\
\text { 4) Training on compliance with accreditation } \\
\text { requirements } \\
\text { 5) Root cause analysis about catastrophic } \\
\text { events and giving feed back to the blood bank }\end{array}$ \\
\hline & $\begin{array}{l}\text { C) Lack of } \\
\text { readability of } \\
\text { request form }\end{array}$ & 2 & 3 & 6 & $\longrightarrow$ & No & Yes & No & $E$ & $\begin{array}{l}\text { 1) Training on and implementation of } \\
\text { principles of registering reports and request } \\
\text { form } \\
\text { 2) Rejecting the unreadable form by the } \\
\text { blood bank }\end{array}$ \\
\hline \multirow{3}{*}{$\begin{array}{l}\text { Ask the patient for MRI } \\
\text { request }\end{array}$} & $\longrightarrow$ & 3 & 3 & 9 & $\longrightarrow$ & No & No & Yes & & \\
\hline & $\begin{array}{l}\text { A) MRI cancellation } \\
\text { and not } \\
\text { implementing it }\end{array}$ & 3 & 3 & 9 & $\longrightarrow$ & No & No & Yes & C & $\begin{array}{l}\text { Healthcare team collaboration-review } \\
\text { of inter ward transfer policy-constant } \\
\text { observation of head of the ward on ward } \\
\text { and during patient transfer }\end{array}$ \\
\hline & $\begin{array}{l}\text { B) Not knowing } \\
\text { about the results }\end{array}$ & 3 & 1 & 3 & $\longrightarrow$ & Yes & - & No & E & $\begin{array}{l}\text { Using PACS system-informing the doctors } \\
\text { about the results }\end{array}$ \\
\hline \multirow{4}{*}{$\begin{array}{l}\text { Delay in initiation of } \\
\text { testing the samples in } \\
\text { laboratory }\end{array}$} & $\longrightarrow$ & 3 & 4 & 12 & $\longrightarrow$ & No & No & Yes & & \\
\hline & $\begin{array}{l}\text { 1) Crowded } \\
\text { laboratory }\end{array}$ & 3 & 4 & 12 & $\longrightarrow$ & No & Yes & No & $A$ & $\begin{array}{l}\text { 1) Reducing the workload and creating shift } \\
\text { table and preventing successive shifts } \\
\text { 2) Providing extra work force } \\
\text { 3) Fitting the workload with number of } \\
\text { human forces } \\
\text { 4) Coordinating the treatment team and } \\
\text { establishing stress management }\end{array}$ \\
\hline & $\begin{array}{l}\text { 2) Lack of } \\
\text { awareness of } \\
\text { importance of the } \\
\text { issue }\end{array}$ & 3 & 3 & 9 & $\longrightarrow$ & No & No & Yes & C & $\begin{array}{l}\text { 1) Holding briefing sessions at the } \\
\text { beginning } \\
\text { 2) Appoint a leader or head for the team } \\
\text { 3) Sharing the information with treatment } \\
\text { team }\end{array}$ \\
\hline & $\begin{array}{l}\text { 3) Lack of } \\
\text { supervision of } \\
\text { technical manager } \\
\text { on procedures }\end{array}$ & 3 & 3 & 9 & $\longrightarrow$ & No & No & Yes & C & $\begin{array}{l}\text { 1) Periodic monitoring and evaluation of } \\
\text { laboratory ward } \\
\text { 2) Checking the competence of team leader } \\
\text { or the responsible person } \\
\text { 3) Monitoring temporal sequence of } \\
\text { process }\end{array}$ \\
\hline
\end{tabular}




\begin{tabular}{|c|c|c|c|c|c|c|c|c|c|c|}
\hline \multicolumn{11}{|l|}{ Table IV. Continue } \\
\hline \multirow{3}{*}{$\begin{array}{l}\text { Lack of patient } \\
\text { cooperation during } \\
\text { sampling }\end{array}$} & $\longrightarrow$ & 3 & 3 & 9 & $\longrightarrow$ & No & No & Yes & & \\
\hline & $\begin{array}{l}\text { 1) Patients fear } \\
\text { specially children } \\
\text { from medical } \\
\text { procedures }\end{array}$ & 3 & 4 & 12 & $\longrightarrow$ & No & No & Yes & A & $\begin{array}{l}\text { 1) Increasing patient knowledge by effective } \\
\text { communication and patient participation } \\
\text { 2) Assessing patient communication ability } \\
\text { with healthcare provider } \\
\text { 3) Providing patient with information }\end{array}$ \\
\hline & $\begin{array}{l}\text { 2) Lack of right } \\
\text { communicat-ion } \\
\text { between patient } \\
\text { and healthcare } \\
\text { providers }\end{array}$ & 3 & 3 & 9 & $\longrightarrow$ & No & No & Yes & C & $\begin{array}{l}\text { 1) Providing patient with information and } \\
\text { consequences of procedures } \\
\text { 2) Administrating topical anesthesia before } \\
\text { LP }\end{array}$ \\
\hline \multirow{3}{*}{$\begin{array}{l}\text { Desterilizing of IV set } \\
\text { by patient caregiver }\end{array}$} & $\longrightarrow$ & 3 & 3 & 9 & $\longrightarrow$ & No & No & Yes & & \\
\hline & $\begin{array}{l}\text { 1) Lack of } \\
\text { patient caregiver } \\
\text { knowledge }\end{array}$ & 3 & 2 & 6 & $\longrightarrow$ & No & No & Yes & C & $\begin{array}{l}\text { 1) Informing patient caregiver about the } \\
\text { type of the procedure } \\
\text { 2) Informing patient about consequences of } \\
\text { each procedure } \\
\text { 3) Advising patient not to interfere in the } \\
\text { care process }\end{array}$ \\
\hline & $\begin{array}{l}\text { 2) Lack of medical } \\
\text { team observation } \\
\text { on ward }\end{array}$ & 3 & 2 & 6 & & No & No & Yes & C & $\begin{array}{l}\text { 1) Holding teamwork training workshops for } \\
\text { all team members } \\
\text { 2) Devising Plans for patient safety } \\
\text { 3) Cooperation of healthcare team }\end{array}$ \\
\hline
\end{tabular}

Hint E: Elimination, C: Control; A: Accept MRI: Magnetic resonance imaging, PACS: Picture archiving communication systems, IV: Intravenous, LP: Lumbar puncture

\begin{tabular}{|c|c|c|c|c|c|c|c|}
\hline $\begin{array}{l}\text { Ward } \\
\text { Strategy } \\
\text { classification }\end{array}$ & Improvement strategy by means of the TRIZ method & 哭 & 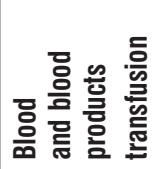 & $\overline{\widetilde{\Sigma}}$ & 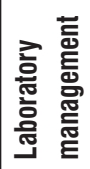 & 오 & 퐁 \\
\hline $\begin{array}{l}\text { Human resources } \\
\text { management }\end{array}$ & $\begin{array}{l}\text { Determination of a supervisor for treatment team, evaluation of the competency } \\
\text { of team leader, conducting periodical assessment and offering feedback to } \\
\text { the personnel, giving treatment team the necessary information, defining the } \\
\text { responsibilities and announcing them, reducing the work load and correcting } \\
\text { the lack of work forces, continuous supervision and controlling the performance } \\
\text { procedures and adjusting the workload with staff }\end{array}$ & 1 & 30 & 7 & 32 & 10 & 80 \\
\hline $\begin{array}{l}\text { Installation } \\
\text { of electronic } \\
\text { prescribing system }\end{array}$ & Implementation procedure on drug combination & 0 & 0 & 0 & 1 & 0 & 1 \\
\hline $\begin{array}{l}\text { Making people } \\
\text { accountable for } \\
\text { patient's safety }\end{array}$ & $\begin{array}{l}\text { Culturally appropriate environment for patient safety and deployment of an incident } \\
\text { reporting system, encouraging the staff to ask question in case of obscurity and } \\
\text { resolving the issue of lack of man power, detachment and pursuing the test results } \\
\text { in form of root analysis of the events and reporting the critical results }\end{array}$ & 0 & 11 & 1 & 5 & 3 & 20 \\
\hline $\begin{array}{l}\text { Medical equipment } \\
\text { management } \\
\text { and process } \\
\text { standardization }\end{array}$ & $\begin{array}{l}\text { Regular calibration of medical equipment, emergency service of medical equipment } \\
\text { and devices, checklists for maintenance of the tools and facility management, } \\
\text { purchasing of protective equipment, creating a qualitative committee and monthly } \\
\text { views of the equipment of Radiology unit. Purchasing safety equipment for safe } \\
\text { transfer }\end{array}$ & 0 & 10 & 3 & 6 & 1 & 20 \\
\hline $\begin{array}{l}\text { Improvement of } \\
\text { patient identification } \\
\text { process }\end{array}$ & $\begin{array}{l}\text { Applying key identifiers in patient identification, improvement of the patient's } \\
\text { recognition processes and revising the guidelines for the correct recognition of } \\
\text { the patients }\end{array}$ & 0 & 8 & 0 & 6 & 0 & 14 \\
\hline $\begin{array}{l}\text { Making clear and } \\
\text { transparent policies } \\
\text { and procedures }\end{array}$ & $\begin{array}{l}\text { The re-engineering of the process, preparing and organizing the executive } \\
\text { guidelines and protocols such as right drug administration, blood transfusion, } \\
\text { IV therapy, care of connections and catheters, inter and intra ward transfer, } \\
\text { preparing new forms with special parts, facilitating the processes and removing } \\
\text { the unnecessary steps, designing a special check-list for evaluation of the patient's } \\
\text { transition between emergency and radiology units, revision policies, simplifying } \\
\text { the process and eliminating unnecessary steps and audits process }\end{array}$ & 0 & 5 & 1 & 2 & 1 & 9 \\
\hline
\end{tabular}




\begin{tabular}{|c|c|c|c|c|c|c|c|}
\hline \multicolumn{8}{|l|}{ Table V. Continue } \\
\hline $\begin{array}{l}\text { Making sure about } \\
\text { availability of suitable } \\
\text { technology for } \\
\text { quality improvement }\end{array}$ & $\begin{array}{l}\text { fundamental improving of the software for entering the physician's commands for } \\
\text { tests-providing PACS system in order to ease the access of experts to MRI }\end{array}$ & 0 & 3 & & 8 & 0 & 11 \\
\hline $\begin{array}{l}\text { Continuous training } \\
\text { and briefing care } \\
\text { providers at the } \\
\text { beginning of } \\
\text { employment }\end{array}$ & $\begin{array}{l}\text { The re-training courses and preparing proper training content according to } \\
\text { the needs of the personnel, the scientific training for prescription writing and } \\
\text { continuous medical training for the physicians, training of recommendation } \\
\text { and instructions, continuing the re-training programs for physicians, training of } \\
\text { recommendation and instructions }\end{array}$ & 1 & 14 & 3 & 0 & 8 & 26 \\
\hline $\begin{array}{l}\text { Participating patients } \\
\text { in treatment process }\end{array}$ & $\begin{array}{l}\text { His/her accompanying person and teaching all the regulations of the sector and } \\
\text { offering the sufficient data and patient's training, patient's contribution by making } \\
\text { effective relationship with them, development of educational patients }\end{array}$ & 3 & 2 & 2 & 12 & 19 & 38 \\
\hline $\begin{array}{l}\text { Implementing and } \\
\text { monitoring suitable } \\
\text { changes in clinical } \\
\text { processes based on } \\
\text { analysis of reliable } \\
\text { data }\end{array}$ & $\begin{array}{l}\text { Continuous supervision, defining the periodical performance assessment criteria } \\
\text { and providing feedback to the personnel, introducing a reference laboratory and } \\
\text { performing some of the important tests randomly in various periods as binary } \\
\text { tests by the hospital laboratory and the reference lab, monitoring on following up } \\
\text { standards. } \\
\text { Taking conscious agreement and explaining probable side effects and risks of } \\
\text { lumbar puncture procedure to the patient or to the patient caregiver }\end{array}$ & 0 & 22 & 1 & 2 & 2 & 27 \\
\hline $\begin{array}{l}\text { Promotion of } \\
\text { communication } \\
\text { amongst treatment } \\
\text { team members }\end{array}$ & Not using abbreviations, obeying the oral commands only in urgent cases & 0 & 2 & 2 & 22 & 1 & 27 \\
\hline Team work & Coordination of treatment team and improving the team relations & 1 & 30 & 5 & 22 & 7 & 65 \\
\hline \multicolumn{2}{|l|}{ Total } & 6 & 137 & 25 & 118 & 52 & 338 \\
\hline
\end{tabular}

IV: Intravenous, MRI: Magnetic resonance imaging, PACS: Picture archiving communication systems, TRIZ: Theory of inventive problem solving

of the patients in the treatment process; $7.9 \%$ related to implementing and monitoring suitable changes in the clinical processes based on the analysis of reliable data; $7.9 \%$ to the promotion of communication amongst the treatment team members, and $19.2 \%$ related to team work.

\section{Discussion}

In this study, according to the five steps for diagnosing the states and effects of health care errors, proposed by the National Center for Safety of The Patient, we identified the possible errors of the selected childhood emergency procedures, the causes of each error situation and the identification of remedial measures. However, with the requirements of the study, changes were made to the proposed model to eliminate model constraints in the implementation. The major changes are: 1) Selecting highrisk processes by voting, using ranking approach, 2) Classifying errors in the framework of nursing error management model, 3) Designing more comprehensive methods to determine the error rate level, 4) Failure factors classification based on the approved model by the UK National Health System; and 5) Failure classification within the framework of medical failure preventive strategies classification model. To prioritize and select the high-risk processes, voting method using rating was used with the study of Taleghani et al. (24) that is consistent in selecting the high-risk process while Anderson et al. (17) used the risk-assessment matrix and the average error score for the selection and periodization of high-risk process in the surgery department. In the present study, the multidisciplinary team was used to identify and assess risk in the pediatric emergency department. Study results of Dominici indicate that in order to evaluate the results of the application effect of HFMEA in the quality of patient care, creating multidisciplinary teams to identify and classify possible risks is important (25). Since the first step in reducing health care errors is to identify the failure modes, a comprehensive model must be used to categorize all failure modes, and help to identify and compare them $(26,27)$. Therefore, we used Nursing Error Management model to group the failure modes of the selected processes in pediatric emergency. In the present study, the most common error related to the care process error in the classes (errors in clinical judgment, errors in caring procedures and continuity of care errors) had $62.3 \%$ prevalence, and was followed by administrative errors in the classes (error in monitoring and planning of the organization and lack of proper management of the organization) with $15.7 \%$. According to the results of the study by Ebrahimipour et al. (7), the most failure modes were in the categories of care errors (63.3\%), administrative errors (15.8\%), communication errors (10.9\%), and knowledge and skill errors $(9.7 \%)$, which is consistent with the results of the present study. In most of the studies with the HFMEA method, the variable of ability to detect failure mode has been eliminated, the reason being that the concept of detection risk is hidden in the indicator of the degree of 
occurrence and the low possibility of discovering the many risks of the health sector (20). If the error report systems in the healthcare sector is applied comprehensively and as a general system in the country, the problem will be resolved (28). In the present study, the incidence and error possibility was determined individually and independently. Independent scoring of team members has the advantage of wearing off the halo effect (cognitive bias caused by an observer's overall impression of a person or situation), which exists in group discussions (17). In this study, all failure modes were classified into one of the following intervention levels based on their hazard score: emergency, urgency, programming, and monitoring. The advantage of this method is that because of the lack of resources of organization, corrective actions and focus on reducing the risk of errors is due to the levels of intervention (19). According to the results of Najafi et al. (29), 52 errors in the process of using Entonox for labor pain as $5.7 \%, 21.1 \%, 26.9 \%$, and $46.1 \%$ were placed in the intervention area of monitoring, emergency, urgency and programming respectively, a finding consistent with our findings here (29). One of the advantages of HFMEA is prioritizing causes which affect all aspects of errors (30). In this study, by using cause and effect analysis, root causes of errors were classified into nine levels of the confirmed model of England National Organization. The most frequent causes of errors were training factors $(18.8 \%)$ and environmental factors (16.1\%). In another study using the HFMEA approach, lack of knowledge and skill are reported to be effective causes of high-risk errors in transferring the patient from the neonatal intensive care unit to the acute care unit (31). In the study of Dehnavieh et al. (27) the most frequent cause of errors in blood transfusion procedure was training factors $(27.2 \%)$, which is compatible with the results of the present study. In a study by Steelman et al. (32), 34.9\% of the causes of high-risk errors identified by HFMEA in the management of retina disorders were reported to be excessive work pressure, doing all the procedures at the same time, and failure in environment design, also compatible with the results of this study. Kositchaiwatet al. (33) reported that the most important causes of medication errors of outpatients were environmental factors (24\%), similar to the results of the present study. Considering the limited resources in any health care organization, the cost of the most effective ones should be chosen to implement strategies and address the causes of the error (27). Therefore, in this study, to determine the proposed strategies, "theory of the problem solving by an inventive method" was used. According to the results of this study, the most preventive measures in selected childhood emergency were grouped in the category of human resource management, team work strategies, and team work. Human resource management strategies are the first ways that organizations can apply to shape individuals' skills, attitudes and behaviors, and thus achieve optimal performance for organizational goals (34). Through this strategy, senior health department executives identify and develop solutions for human resource issues (35). According to Taleghani et al. (24) and Ebrahimipour et al. (7), using the strategy of human resources management is the most important strategy to improve patient safety and reduce clinical errors. Team work strategy is an approach to develop communication among the health unit personnel who work separately in order to improve healthcare (36). Efficient team work depends on effective communication between team members and sufficient organization source. Compatibility with standard equipment and behavior is an effective strategy to improve team work morale (37). In a retrospective study, results showed that by implementing team work improvement strategies, $18 \%$ of the death rate in 74 training hospitals had decreased (38). According to O'leary et al. (39) and the National Society of Accreditation Commission, quality and patient safety depend on team work $(39,40)$. Since the most prevalent errors in the researches of this field pertains to implementation and care errors, the following solutions are placed as executive orders on the agenda of the Ghaem Emergency Department: "Audit and re-engineering key emergency processes", "Providing and developing policies, and procedures such as checking doctor's orders, taking care of fittings and catheters, and identifying the patient", "Written job descriptions for personnel and its notification", "Compilation of personnel performance assessment criteria and periodic evaluation and feedback to personnel", "Designing educational content tailored to the needs of employees", "Reducing labor load and eliminating shortages of human resources", "Observing effective communication with the patient and in the form of patient education programs", "Continuation of retraining programs for the treatment staff", "Training recommendations and guidelines and monitoring compliance with standards", "Determining the critical scale for experiments", "Designing a special checklist for assessing the transfer of the patient from the ward to the MRI section", "Formation of the quality committee and monthly inspections of the equipment of the support department", "Promotion of collaborating", "Equipment Management", "Providing Pix system for easy access to the MRI photos by experts", "Getting informed consent and describing the possible complications and possible risks of carrying out the process of cerebrospinal fluid to the patient or the associate", "Using a patient identification bracelet", "The establishment of the blood transfer system", "Setting regular schedules for sending samples and receiving answers "and "monitoring the correct fitting". Finally, the utility of HFMEA has been proven in the redesigning of the health sector processes. However, successful implementation of this approach is associated with a strong and effective leadership and a continuing commitment to prevention (41). Latino and flood (42), had similar views on the role of leadership and organizational management in the successful implementation of risk management practices. It should be noted that the implementation of strategies and proposed actions have a strong relationship with team participation of the individuals, and financial and administrative support of the organization's 
leader (20). So, the successful implementation of prospective risk assessment programs are related to the strong and effective leadership and continuous commitment of the director (42)

\section{Study Limitation}

One of the limitations of this study, and of all studies that use the HFMEA approach, is that showing a decrease in the probability of occurrence of adverse events is difficult after conducting interventions; thus, one cannot prove the improvement of the patients' safety or do cost-benefit analysis by using HFMEA programs (21). Also, the high risk errors in each organization are determined based on the atmosphere and environment of that organization, and the results cannot be compared with other organizations and even other departments of the hospital because the frequency and severity of errors differ in the same departments of different hospitals.

\section{Conclusion}

Using the proactive method of HFMEA for identifying the possible failure of treatment procedures, determining the effective cause on each failure mode and proposing the improvement strategies, has a high efficiency and effectiveness. So HFMEA should be implemented continually as a risk assessment model in healthcare organizations. Their application can reduce the occurrence of failures and their outcomes to the minimum possible level and provide a basis for quality improvement and risk reduction. Also, the application of systematic and regular proactive risk management techniques, along with the commitment of managers and the organization policies renewal can ensure the effectiveness of these activities.

\section{Acknowledgements}

We would like to thank all the people who helped us to perform this study especially Pediatric Emergency personnel of Mashhad.

\section{Ethics}

Ethics Committee Approval: This study was approved by the ethical committee of Mashhad University of Medical Sciences prior to the collection of the data in January 2013 (approval number: 911089).

Informed Consent: Written informed consent was recruited from each participant.

Peer-review: External and internal peer-reviewed.

\section{Authorship Contributions}

Surgical and Medical Practices: Y.M.T., Concept: Y.M.T., Design: H.S., Data Collection or Processing: A.A., Analysis or Interpretation: M.N.M., Literatur Search: Y.M.T., H.S., Writing: H.S.

Conflict of Interest: No conflict of interest was declared by the authors.

Financial Disclosure: The authors declared that this study received no financial support.

\section{References}

1. Adachi W, Lodolce AE. Use of failure mode and effects analysis in improving the safety of i.v. drug administration. Am J Health Syst Pharm 2005;62:917-20.

2. Singer $S$, Lin $S$, Falwell $A$, Gaba D, Baker L. Relationship of safety climate and safety performance in hospitals. Health Serv Res 2009;44: 399-421.

3. Burström L. Patient Safety in the Emergency Department: Culture, Waiting, and Outcomes of Efficiency and Quality. 2014.

4. Foley EM, Wolfe RE, Burstein JL, Edlow JA, Grossman SA. Utility of Procedural Sedation as a Marker for Quality Assurance in Emergency Medicine. J Emerg Med 2016;50:711-4.

5. Dabaghzadeh F, Rashidian A, Torkamandi H, et al. Medication errors in an emergency department in a large teaching hospital in tehran. Iran J Pharm Res 2013;12:937-42.

6. Wente SJ. Nonpharmacologic pediatric pain management in emergency departments: a systematic review of the literature. J Emerg Nurs J Emerg Nurs 2013;39:140-50.

7. Ebrahimipour $\mathrm{H}$, Taleghani YM, Najar AV. Proactive risk assessment of the laboratory management process inGhaem Hospital, Mashhad. Journal of Paramedical Sciences 2015;6:85-95.

8. Nagpal K, Vats A, Ahmed K, et al. A systematic quantitative assessment of risks associated with poor communication in surgical care. Arch Surg 2010;145:582-8.

9. DeRosier J, Stalhandske E, Bagian JP, Nudell T. Using health care failure mode and effect analysis ${ }^{\mathrm{TM}}$ : the VA National Center for Patient Safety's prospective risk analysis system. Jt Comm J Qual Improv 2002;28:248-67.

10. Cheng $\mathrm{CH}$, Chou CJ, Wang PC, Lin HY, Kao CL, Su CT, et al. Applying HFMEA to prevent chemotherapy errors. J Med Syst 2012;36:1543-51.

11. Eadie A. Medical error reporting should it be mandatory in Scotland? J Forensic Leg Med 2012;19:437-41.

12. Shahrami A, Rahmati F, Kariman $\mathrm{H}$, et al. Utilization of Failure Mode and Effects Analysis (FMEA) Method in Increasing the Revenue of Emergency Department; a Prospective Cohort Study. Emergency (Tehran) 2013;1:1-6.

13. Wente SJ. Nonpharmacologic pediatric pain management in emergency departments: a systematic review of the literature. J Emerg Nurs 2013;39:140-50.

14. Chanamool N, Naenna T. Fuzzy FMEA application to improve decision-making process in an emergency department. Applied Soft Computing 2016;43:441-53.

15. Pour HE, Taleghani YM, Najar AV, Vejdani M, Heydarabadi $A B$, Hafez AA. Risk assessment of the selected processes in women's surgery ward by Healthcare Failure Mode and Effecr Analysis (HFMEA) method, 2013. International Research Journal of Applied and Basic Science 2015;9:58795.

16. Attar Jannesar Nobari F, Tofighi SH, Hafezimoghadam $P_{1}$ Maleki MR, Goharinezhad S. Risk assessment of processes of rasoule akram emergency department by the failure mode and effects analysis (FMEA) methodology. Hakim Research Journal 2010;3:165-76.

17. Anderson O, Brodie A, Vincent CA, Hanna GB. A systematic proactive risk assessment of hazards in surgical wards: a quantitative study. Ann Surg 2012;255:1086-92. 
18. Tran DT, Johnson M. Classifying nursing errors in clinical management within an Australian hospital. Int Nurs Rev 2010;57:454-62

19. Bonfant G, Belfanti P, Paternoster G, et al. Clinical risk analysis with failure mode and effect analysis (FMEA) mode in a dialysis unit. J Nephrol 2010;23:111-8.

20. Spath PL. Using failure mode and effects analysis to improve patient safety. AORN J 2003;78:16-37.

21. Linkin DR, Sausman C, Santos L, Lyons C, Fox C, Aumiller L, Esterhai J, Pittman B, Lautenbach E. Applicability of healthcare failure mode and effects analysis to healthcare epidemiology: evaluation of the sterilization and use of surgical instruments. Clin Infect Dis. 2005;41:1014-9. Epub 2005 Aug 30

22. Livotov P, Petrov V. TRIZ and Innovation Technology. Product Development and Inventive Problem Solving. INNOVATOR Tris Europe, 2013.

23. Nasiripour AA, Arani LK, Raessi P, Tabib J. Development and compilation of strategies and preventive measures for medical errors in public hospitals in Tehran. Journal of Health Administration 2011;14:21-32.

24. Taleghani YM, Rezaei F, Sheikhbardsiri H. Risk assessment of the emergency processes: Healthcare failure mode and effect analysis. World J Emerg Med 2016;7:97-105.

25. Dominici L, Nepomnayshy D, Brown T, O'Brien P, Alden D, Brams D. P113: Implementation of HFMEA in a bariatric surgery program improves the quality and culture of care. Surgery for Obesity and Related Diseases 2006;2:346-7.

26. Steele C, Rubin G, Fraser S. Error classification in community optometric practice-a pilot project. Ophthalmic Physiol Opt 2006;26:106-10.

27. Dehnavieh $R$, Ebrahimipour $H$, Molavi-Taleghani $Y$, et al. Proactive Risk Assessment of Blood Transfusion Process, in Pediatric Emergency, Using the Health Care Failure Mode and Effects Analysis (HFMEA). Glob J Health Sci 2014; 7:322-31.

28. Rezaei F, Yarmohammadian MH, Ferdosi M, Haghshenas A. Developing an integrated clinical risk management model for Hospitals. International Journal of Health System and Disaster Management 2013;1:221-8.

29. Najafi TF, Bahri N, Ebrahimipour $H$, Najar AV, Taleghani YM. Risk Assessment of Using Entonox for the Relief of Labor Pain: A Healthcare Failure Modes and Effects Analysis Approach. Electron Physician 2016:8:2150-9.
30. Collins CM, Elsaid KA. Using an enhanced oral chemotherapy computerized provider order entry system to reduce prescribing errors and improve safety. Int J Qual Health Care 2011;23:36-43.

31. Moyer VA, Singh H, Finkel KL, Giardino AP. Transitions from neonatal intensive care unit to ambulatory care: description and evaluation of the proactive risk assessment process. Qual Saf Health Care 2010;19(Suppl 3):26-30.

32. Steelman VM, Cullen JJ. Designing a safer process to prevent retained surgical sponges: a healthcare failure mode and effect analysis. AORN J 2011;94:132-41.

33. Kositchaiwat J, Ratchatawijin $M$, Bamroungwongpat $A$, Boriboonwate U. System Approach of Medication Error in Prapokklao Hospital. J Prapokklao Hosp Clin Med Educat Center 2005.22:5-19.

34. Nasiri M, Heidari M, Shahbazi S, Ansari E. Correlation of human resource strategies based on Allen Ylsy Model with organizational performance staff in Aiat Allah Kashani Hospital. Journal of Health Promotion Management 2013;2:36-44.

35. Wong J, Beglaryan $\mathrm{H}$. Association, Strategies for hospitals to improve patient safety: a review of the research. Change Foundation, 2004.

36. Oandasan I, Baker GR. Teamwork in Healthcare: Promoting effective teamwork in healthcare in Canada. Canadian Health Services Research Foundation, 2006.

37. Baker, Gustafson S, Beaubien J, Salas E, Barach P. Medical Teamwork and Patient Safety The Evidence-based Relation. Agency for Healthcare Research and Quality, 2005.

38. Pronovost PJ, Freischlag JA. Improving teamwork to reduce surgical mortality. JAMA 2010;304:1721-2.

39. O'leary KJ, Sehgal NL, Terrell G, Williams MV. Interdisciplinary teamwork in hospitals: a review and practical recommendations for improvement. Journal of hospital medicine 2012;7:48-54.

40. Coburn AF, Croll ZG. Improving Hospital Patient Safety Through Teamwork: The Use of TeamSTEPPS In Critical Access Hospitals. Flex Monitoring Team With Funding From The Federal Office of Rural Health Policy 2011:2-12.

41. Duwe B, Fuchs BD, Hansen-Flaschen J. Failure mode and effects analysis application to critical care medicine. Crit Care Clin 2005;21:21-30, vii.

42. Latino RJ, Flood A. Optimizing FMEA and RCA efforts in health care. J Healthc Risk Manag 2004;24:21-8. 